\title{
Joint Production and Disposal Decisions for Sustainable Operations of the Hybrid Production System
}

\author{
Eungab Kim ${ }^{\dagger}$ \\ College of Business Administration, Ewha Womans University \\ 혼성 생산 시스템의 지속 가능 운영을 위한
신제품 생산과 회수제품 수용 통제의 통합 구현 \\ 김 은 갑 \\ 이화여자대학교 경영대학 경영전문대학원

\begin{abstract}
We consider a reverse supply chain with a production facility and a recovery facility, and address the joint control of production and disposal decisions for sustainable operations. Demands are satisfied from on-hand inventory of serviceable products, replenished via manufacturing or remanufacturing. Sold products may be returned after usage and each returned product is disposed of or accepted for recovery. Accepted returned products are converted into serviceable products after remanufacturing process. Formulating the model as a Markov decision process, we characterized the structure of the optimal production and disposal policy as two monotone switching curves under a special condition. Three types of heuristic policies are presented and their performance is numerically compared.
\end{abstract}

Keywords: Reverse Supply Chain, Product Return, Sustainable Operations, Recovery, Disposal

\section{Introduction}

Remanufacturing is not only an important step toward sustainability, but is also economically beneficial for firms. Therefore, many firms implement collection channels for used product return and integrate corresponding remanufacturing strategies with their regular production system (Li et al., 2013). Considering the economic benefits from a cheaper remanufacturing, it might be also cost-effective in some industries to consider disposing of returned items, since an increase in the inventory of returned products may be too costly (Teunter and Vlachos, 2002; van der Lann et al., 1996a). This research is a step toward rationalizing such decisions. In this paper, we generate insights into how production of new products and disposal of returned items can be effectively coordinated in a hybrid production system with manufacturing and remanufacturing. Such coordination will provide financial incentives for firms to move toward sustainable operations.

This paper considers a single type of product stocked in order to meet random demand from customers who may return products after usage. Demands are satisfied from onhand inventory of products, replenished via manufacturing or remanufacturing. Unmet demand is lost. Product returns occur randomly and each returned item is disposed of or accepted for recovery. Accepted ones are converted into products and are as good as newly produced ones. The assumption of the equal quality is valid in some real cases. For example, Zhou et al. (2011) considered a large energy company which provides service on meters and transformers for private houses

\footnotetext{
This work was supported by the National Research Foundation of Korea Grant funded by the Korean Government (NRF-2011-327-B00223).

† Corresponding Author : Professor Eungab Kim, College of Business Administration, Ewha Women's University, Daehyeon-dong, Seodaemun-gu, Seoul, 120-750, Korea, Tel : +82-2-3277-3970, Fax : +82-2-3277-2835, E-mail : evanston@ewha.ac.kr Received August 15, 2012; Revision Received March 28, 2013; Accepted May 20, 2013.
} 
and commercial buildings and recovers all failed meters/ transformers. In this case, customers are indifferent between a new product and a remanufactured one.

Although there has been substantial research into the production planning and inventory management in a hybrid system, relatively few papers have addressed the product recovery with a disposal option. Heyman (1977) presented a continuous inventory review model with zero lead times for remanufacturing and procurement processes. Under Poisson demand and return processes, the optimality of a single parameter disposal policy is shown. Simpson (1978) studied a periodic inventory review model where unmet demand is backlogged and zero lead times are assumed for purchase and recovery processes, and show that a three-parameter policy is optimal to control manufacturing, remanufacturing, and disposal. Inderfurth (1997) studied the effect of deterministic replenishment and remanufacturing lead times on the optimal policy, and show that the policy identified in Simpson (1978) is also optimal for identical deterministic lead times. van der Lann et al. (1996a) studied a continuous inventory review model with Poisson demand and returns in which the number of remanufacturable products is limited to a level. van der Lann et al. (1996b) show, based on a numerical study, that there is an advantage of making disposal decisions based on both remanufacturable and serviceable inventory levels rather than only based on the remanufacturable inventory level. Using simulation, Teunter and Vlachos (2002) showed that disposal option can result in a significant cost reduction only when an item is very slow moving, the recovery rate is high, and remanufacturing is almost as expensive as manufacturing.

Detailed literature reviews for inventory management of a hybrid production system are summarized in $<$ Table $1>$. We classify the references using the following characteristics : 1 . Inventory review (periodic or continuous), 2. Production and remanufacturing lead time (stochastic, constant, or zero), 3. Type of inventory holding (serviceable, remanufacturable), 4. Type of unit costs (production, remanufacturing, disposal), 5. Type of control (production, disposal), 6. Identification of optimal policy (yes or no), 7. Stockout treatment (backlog or lost sales).

Our model contributes to this stream of research in several ways. First, we coordinate decisions of when to produce a new product and dispose of a returned item based on the levels of both serviceable and remanufacturable inventories. Second, we identify the optimal policy under a continuous inventory review. Previous studies with continuous inventory review have mainly tried to find optimal parameters for given policies rather than characterizing the optimal policy. This is partially due to the complexity of the underlying control problem when lead times are stochastic. Heyman (1977) and Inderfurth (2001) identified the optimal policy under a continuous inventory review. But Heyman (1977) did not consider lead time and Inderfurth (2001) assumed constant lead time. Third, we develop effective and implementable heuristic policies

Table 1. Summary of literature survey $(\mathrm{PR}=$ periodic review, $\mathrm{CR}=$ continuous review, $\mathrm{M}=$ manufacturing, $\mathrm{R}=$ remanufacturing, $\mathrm{D}=$ disposal, $H_{1}=$ serviceable inventory, $H_{2}=$ remanufacturable inventory, $\mathrm{B}=$ backlog, $\mathrm{L}=$ lost sales, Exp $=$ Exponential random variable, $\mathrm{Dis}=$ Discrete random variable)

\begin{tabular}{|c|c|c|c|c|c|c|c|c|c|c|c|c|c|c|c|c|c|c|}
\hline \multirow{3}{*}{$\begin{array}{c}\text { Articles } \\
\text { (indexed by the first } \\
\text { author) }\end{array}$} & \multirow{2}{*}{\multicolumn{2}{|c|}{$\begin{array}{c}\text { Inventory } \\
\text { review }\end{array}$}} & \multicolumn{6}{|c|}{ Lead Time } & \multirow{2}{*}{\multicolumn{2}{|c|}{ Holding }} & \multirow{2}{*}{\multicolumn{3}{|c|}{$\begin{array}{l}\text { Unit } \\
\text { cost }\end{array}$}} & \multirow{2}{*}{\multicolumn{2}{|c|}{ Control }} & \multirow{3}{*}{$\begin{array}{l}\text { Opt. } \\
\text { policy }\end{array}$} & \multirow{2}{*}{\multicolumn{2}{|c|}{$\begin{array}{c}\text { Stock } \\
\text { out }\end{array}$}} \\
\hline & & & \multicolumn{2}{|c|}{ Stochastic } & \multicolumn{2}{|c|}{ Constant } & \multicolumn{2}{|c|}{ Zero } & & & & & & & & & & \\
\hline & PR & $\mathrm{CR}$ & $\mathrm{M}$ & $\mathrm{R}$ & $\mathrm{M}$ & $\mathrm{R}$ & $\mathrm{M}$ & $\mathrm{R}$ & $H_{1}$ & $\mathrm{H}_{2}$ & $\mathrm{M}$ & $\mathrm{R}$ & $\mathrm{D}$ & $\mathrm{M}$ & $\mathrm{D}$ & & $\mathrm{B}$ & $\mathrm{L}$ \\
\hline DeCroix, 2006 & $\mathrm{O}$ & & & & $\mathrm{O}$ & $\mathrm{O}$ & & & $\mathrm{O}$ & $\mathrm{O}$ & $\mathrm{O}$ & $\mathrm{O}$ & $\mathrm{O}$ & $\mathrm{O}$ & $\mathrm{O}$ & $\mathrm{O}$ & $\mathrm{O}$ & \\
\hline Fleischmann, 2003 & & $\mathrm{O}$ & & & $\mathrm{O}$ & & & & $\mathrm{O}$ & & & & & $\mathrm{O}$ & & & $\mathrm{O}$ & \\
\hline Heyman, 1977 & & $\mathrm{O}$ & & & & & $\mathrm{O}$ & $\mathrm{O}$ & $\mathrm{O}$ & & $\mathrm{O}$ & & $\mathrm{O}$ & & $\mathrm{O}$ & $\mathrm{O}$ & $\mathrm{O}$ & \\
\hline Inderfurth, 1997 & $\mathrm{O}$ & & & & $\mathrm{O}$ & $\mathrm{O}$ & & & $\mathrm{O}$ & $\mathrm{O}$ & $\mathrm{O}$ & $\mathrm{O}$ & $\mathrm{O}$ & $\mathrm{O}$ & $\mathrm{O}$ & $\mathrm{O}$ & $\mathrm{O}$ & \\
\hline Inderfurth, 2001 & & $\mathrm{O}$ & & & $\mathrm{O}$ & $\mathrm{O}$ & & & $\mathrm{O}$ & $\mathrm{O}$ & $\mathrm{O}$ & $\mathrm{O}$ & $\mathrm{O}$ & $\mathrm{O}$ & $\mathrm{O}$ & $\mathrm{O}$ & & \\
\hline Mahadevan, 2003 & & $\mathrm{O}$ & & & $\mathrm{O}$ & $\mathrm{O}$ & & & $\mathrm{O}$ & $\mathrm{O}$ & & & & $\mathrm{O}$ & & & $\mathrm{O}$ & \\
\hline Muckstadt, 1981 & & $\mathrm{O}$ & & & $\mathrm{O}$ & & & & $\mathrm{O}$ & & & & & $\mathrm{O}$ & & & $\mathrm{O}$ & \\
\hline Simpson, 1978 & $\mathrm{O}$ & & & & & & $\mathrm{O}$ & $\mathrm{O}$ & $\mathrm{O}$ & $\mathrm{O}$ & $\mathrm{O}$ & $\mathrm{O}$ & & $\mathrm{O}$ & $\mathrm{O}$ & $\mathrm{O}$ & $\mathrm{O}$ & \\
\hline Teunter, 2002 & $\mathrm{O}$ & & & & $\mathrm{O}$ & $\mathrm{O}$ & & & $\mathrm{O}$ & $\mathrm{O}$ & $\mathrm{O}$ & $\mathrm{O}$ & $\mathrm{O}$ & $\mathrm{O}$ & $\mathrm{O}$ & & $\mathrm{O}$ & \\
\hline Teunter, 2004 & & $\mathrm{O}$ & & & $\mathrm{O}$ & $\mathrm{O}$ & & & $\mathrm{O}$ & $\mathrm{O}$ & & & & $\mathrm{O}$ & & & $\mathrm{O}$ & \\
\hline van der Laan, 1996a & & $\mathrm{O}$ & & Exp & $\mathrm{O}$ & & & & $\mathrm{O}$ & $\mathrm{O}$ & & & & $\mathrm{O}$ & $\mathrm{O}$ & & $\mathrm{O}$ & \\
\hline van der Laan, 1996b & & $\mathrm{O}$ & & Exp & $\mathrm{O}$ & & & & $\mathrm{O}$ & $\mathrm{O}$ & $\mathrm{O}$ & $\mathrm{O}$ & $\mathrm{O}$ & $\mathrm{O}$ & $\mathrm{O}$ & & $\mathrm{O}$ & \\
\hline van der Laan, 1997 & & $\mathrm{O}$ & & & $\mathrm{O}$ & $\mathrm{O}$ & & & $\mathrm{O}$ & & & & & $\mathrm{O}$ & $\mathrm{O}$ & & $\mathrm{O}$ & \\
\hline van der Laan, 1999a & & $\mathrm{O}$ & Dis & Dis & & & & & $\mathrm{O}$ & $\mathrm{O}$ & $\mathrm{O}$ & $\mathrm{O}$ & $\mathrm{O}$ & $\mathrm{O}$ & & & $\mathrm{O}$ & \\
\hline van der Laan, 1999b & & $\mathrm{O}$ & & & $\mathrm{O}$ & $\mathrm{O}$ & & & $\mathrm{O}$ & $\mathrm{O}$ & $\mathrm{O}$ & $\mathrm{O}$ & & $\mathrm{O}$ & & & $\mathrm{O}$ & \\
\hline van der Laan, 2006 & & $\mathrm{O}$ & & & $\mathrm{O}$ & $\mathrm{O}$ & & & $\mathrm{O}$ & $\mathrm{O}$ & $\mathrm{O}$ & $\mathrm{O}$ & & $\mathrm{O}$ & & & $\mathrm{O}$ & \\
\hline Wei, 2009 & $\mathrm{O}$ & & & & $\mathrm{O}$ & $\mathrm{O}$ & & & $\mathrm{O}$ & $\mathrm{O}$ & $\mathrm{O}$ & $\mathrm{O}$ & $\mathrm{O}$ & $\mathrm{O}$ & $\mathrm{O}$ & & $\mathrm{O}$ & \\
\hline Our model & & $\mathrm{O}$ & Exp & Exp & & & & & $\mathrm{O}$ & $\mathrm{O}$ & $\mathrm{O}$ & $\mathrm{O}$ & $\mathrm{O}$ & $\mathrm{O}$ & $\mathrm{O}$ & $\mathrm{O}$ & & $\mathrm{O}$ \\
\hline
\end{tabular}


which provide firms with a simple tool to achieve higher profits while encouraging the use of sustainable operations.

The remainder of the paper is organized as follows. In Section 2, we present our model. Analysis of the optimal policy is given in Section 3. In Section 4, we implement a sensitivity analysis on the optimal policy. In Section 5, we present a computational study of the optimal and heuristic policies. Finally, we conclude in Section 6.

\section{Model Assumptions and Problem Formulation}

Demands for a single product arrive according to a Poisson process with rate $\lambda_{1}$. If demand is satisfied from on-hand inventory, a revenue of $R$ is generated. Hereafter, we refer to the on-hand inventory as serviceable inventory. Each unmet demand due to stockout is lost. The production time of a new item is exponentially distributed with mean $\mu_{1}^{-1}$. Arrival of returned products follows a Poisson process with rate $\lambda_{2}$. Similar to the production process, recovery is performed item by item (i.e., no batching). The remanufacturing time is exponentially distributed with mean $\mu_{2}^{-1}$. Holding costs are assessed at rate $h_{1}$ and $h_{2}$ for each unit in serviceable and remanufacturable inventory, respectively. We assume that $h_{1} \geq h_{2}$. Unit production and remanufacturing costs are $c_{M}$ and $c_{R}$, respectively. Disposing of a returned product incurs $c_{D}$ where $c_{D}<0$ implies a salvage value.

Although the return process may be affected by the previous sales, we assume that demand process does not influence the rate of return. If there are large quantities of sold products in the market, the independence assumption will be reasonable. It can also serve as a reasonable approximation in solving many practical problems by yielding easily implementable control policies. See Fleischmann (2000) for detailed justification of the independence assumption.

At each epoch of a demand arrival, a product return, a production completion, or a remanufacturing completion, a control policy specifies whether or not to produce a new item. Upon a product return, a decision must be made regarding whether to dispose of or accept it. A state is described by the vector $\left(x_{1}, x_{2}\right)$ where $x_{1}$ and $x_{2}$ represent the serviceable and remanufacturable inventory level, respectively. We denote the state space by $\Gamma$.

The goal of this paper is to identify a joint production and disposal control policy that maximizes the long-run average profit. To this end, we formulate our model as a discrete-time Markov Decision Process (MDP) problem with a transition rate $\gamma \equiv \lambda_{1}+\lambda_{2}+\mu_{1}+\mu_{2}$. The properties and insights provided in this paper can be useful for understanding and addressing more realistic models with non-exponential distributions where it is not tractable to identify the optimal policy.
Let $v\left(x_{1}, x_{2}\right)$ be the optimal profit function in state $\left(x_{1}, x_{2}\right)$. We define the value iteration operator $T$ on $v$ as :

$$
\begin{aligned}
& \operatorname{Tv}\left(x_{1}, x_{2}\right)=\frac{1}{\gamma}\left[-\left(x_{1} h_{1}+x_{2} h_{2}\right)\right. \\
& +\lambda_{1}\left\{\left(R+v\left(x_{1}-1, x_{2}\right)\right) 1\left(x_{1}>0\right)+v\left(x_{1}, x_{2}\right) 1\left(x_{1}=0\right)\right\} \\
& +\mu_{1} \max \left\{-c_{M}+v\left(x_{1}+1, x_{2}\right), v\left(x_{1} x_{2}\right)\right\} \\
& +\mu_{2}\left\{\left(v\left(x_{1}+1, x_{2}-1\right)-c_{R}\right) 1\left(x_{2}>0\right)+v\left(x_{1}, x_{2}\right) 1\left(x_{2}=0\right)\right\} \\
& \left.+\lambda_{2} \max \left\{v\left(x_{1}, x_{2}+1\right), v\left(x_{1}, x_{2}\right)-c_{D}\right\}\right]
\end{aligned}
$$

where $1(a)=1$ if $a$ is true, otherwise, 0 . In (1), $-\left(x_{1} h_{1}+\right.$ $\left.x_{2} h_{2}\right) / \gamma$ is the average holding costs of $x_{1}$ units and $x_{2}$ units until the next state transition. The terms multiplied by $\lambda_{1}$ and $\lambda_{2}$ represent the sales revenue and transition generated with a demand arrival and the cost and transition associated with a product return. The terms multiplied by $\mu_{1}$ and $\mu_{2}$ implies the costs and transitions associated with a production completion and a recovery completion. Then, the optimality equation of our MDP model can be written as

$$
g+v\left(x_{1}, x_{2}\right)=T v\left(x_{1}, x_{2}\right)
$$

where $g$ is the optimal average profit during the expected state transition time $\gamma^{-1}$.

\section{Structure of the Optimal Production and Disposal Policy Under the Special Case}

In this section, we characterize the structure of the optimal production and disposal policy under the assumption of $h_{1}=h_{2}$. When $h_{1}>h_{2}$, we could not complete the proof of the existence of the optimal policy, although it is a more practical assumption. The condition $h_{1}=h_{2}$ guarantees that it is always advantageous to convert the returned products into the serviceable ones as long as $x_{2}>0$, that is, $f\left(x_{1}+1\right.$, $\left.x_{2}\right)-c_{R} \geq f\left(x_{1}, x_{2}+1\right)$. When $h_{1}>h_{2}$, however, the above equation cannot be confirmed. One might think that it is a better policy to postpone the remanufacturing until it is required when $h_{1}>h_{2}$. For example, when $x_{1}$ is large enough to cope with demand, the replenishment of serviceable product via remanufacturing could not be cost-effective. This indicates that the control of remanufacturing as well as production and disposal will become important for more efficient operation of a hybrid production system. We will cover this issue in the future research.

To prove the structure of the optimal production and disposal policy, we identify a set of structured profit functions is preserved under the value iteration operator $T$ (Porteus, 1982). Define $D_{i} f i=1,2$, on any real valued function $f$ : 


$$
\begin{aligned}
& D_{1} f\left(x_{1}, x_{2}\right) \equiv f\left(x_{1}+1, x_{2}\right)-f\left(x_{1}, x_{2}\right), \\
& D_{2} f\left(x_{1}, x_{2}\right) \equiv f\left(x_{1}, x_{2}+1\right)-f\left(x_{1}, x_{2}\right) .
\end{aligned}
$$

$D_{1} f\left(D_{2} f\right)$ is the marginal value of having one more unit in serviceable (remanufacturable) inventory. Let $F$ be the set of all functions defined on state space $\Gamma$ such that if $f \in F$, then

$$
\begin{gathered}
D_{i} f\left(x_{i}, x_{j}\right) \geq D_{i} f\left(x_{i}, x_{j}+1\right), \\
i \neq j, i=1,2, j=1,2, \\
D_{i} f\left(x_{i}, x_{j}+1\right) \geq D_{i} f\left(x_{i}+1, x_{j}\right), \\
i \neq j, i=1,2, j=1,2, \\
D_{i} f\left(x_{i}, x_{j}\right) \geq D_{i} f\left(x_{i}+1, x_{j}\right), \\
i \neq j, i=1,2, j=1,2, \\
D_{1} f\left(x_{1}, x_{2}\right) \leq R, \\
f\left(x_{1}+1, x_{2}\right)-c_{R} \geq f\left(x_{1}, x_{2}+1\right) .
\end{gathered}
$$

Equation (2) states that $f$ is submodular, which implies that the marginal benefit of holding one more unit of one inventory decreases as the other inventory increases. Equation (3) implies that the marginal value of having one more unit of one inventory decreases faster in its inventory than in the other inventory. Equation (4) says that $f$ is concave in its coordinates, which means that the incremental benefit with one more unit of one inventory is decreasing in its inventory. Note that (2) and (3) together imply concavity. Equation (6) says that it is always advantageous to convert the returned product into the serviceable one.

The following lemma guarantees that equations (2)-(6) are preserved under $T$. The proof of this and all subsequent results are included in the Appendix.

Lemma 1 : If $f \in F, T f \in F$.

The following theorem identifies the structural properties of the optimal policy :

\section{Theorem 1.}

(i) There exists an optimal average profit, $g$, and an optimal profit function, $v$, which satisfy (1), and $v \in F$.

(ii) Let

$$
\begin{aligned}
& P\left(x_{2}\right) \equiv \max \left\{x_{1}: v\left(x_{1}, x_{2}\right) \leq v\left(x_{1}+1, x_{2}\right)-c_{M}\right\}, \\
& D\left(x_{1}\right) \equiv \min \left\{x_{2}: v\left(x_{1}, x_{2}+1\right) \leq v\left(x_{1}, x_{2}\right)-c_{D}\right\}
\end{aligned}
$$

In state $\left(x_{1}, x_{2}\right)$, it is optimal to produce an item if $x_{1} \leq$ $P\left(x_{2}\right)$. When a product return occurs, it is optimal to disposes of this return if $x_{2} \geq D\left(x_{1}\right)$, otherwise, accepts it for recovery. (iii) $P\left(x_{2}\right)$ decreases in $x_{2}$.

(iv) $D\left(x_{1}\right)$ decreases in $x_{1}$.

The structure of the optimal policy is characterized by two monotone stitching curves $P\left(x_{2}\right)$ and $D\left(x_{1}\right)$. Part (ii) states that if $D_{1} v \geq c_{M}$, it is beneficial to increase $x_{1}$ by one unit. It also says that if $D_{2} v \leq-c_{D}$, it should dispose of a returned item. Parts (iii) and (iv) state that it is optimal to keep less of one inventory as the other inventory increases, which follows from the submodularity of $v$. Since a returned item, once recovered, is perfectly converted into a serviceable product, if more units are stored in one inventory, it is cost-effective to store less units of the other inventory.

\section{Marginal Effects of Problem Parameters on the Optimal Policy}

Suppose that product returns are controlled by a threshold, $M$. In other words, a product return is accepted for recovery only when $x_{2}<M$ and, otherwise, disposed of. We then investigate how the system parameters affect $P\left(x_{2}\right)$. Consider the following optimization problem :

$$
\begin{aligned}
& v\left(x_{1}, x_{2}\right)+g=\frac{1}{\gamma}\left[-x_{1} h_{1}-x_{2} h_{2}\right. \\
& +\lambda_{1}\left\{\left(R+v\left(x_{1}-1, x_{2}\right)\right) 1\left(x_{1}>0\right)+v\left(x_{1}, x_{2}\right) 1\left(x_{1}=0\right)\right\} \\
& +\mu_{1} \max \left\{-c_{M}+v\left(x_{1}+1, x_{2}\right), v\left(x_{1}, x_{2}\right)\right\} \\
& +\mu_{2}\left\{\left(v\left(x_{1}+1, x_{2}-1\right)-c_{R}\right) 1\left(x_{2}>0\right)+v\left(x_{1}, x_{2}\right) 1\left(x_{2}=0\right)\right\} \\
& \left.+\lambda_{2}\left\{f\left(x_{1}, x_{2}+1\right) 1\left(x_{2}<M\right)+\left(f\left(x_{1}, x_{2}\right)-c_{D}\right) 1\left(x_{2}=M\right)\right\}\right]
\end{aligned}
$$

Then, using the same arguments as in Section 3, one can show the existence of $P\left(x_{2}\right)$ as it is defined in Theorem 1 . We first present the effects of the cost parameters on $P\left(x_{2}\right)$ :

\section{Theorem 2.}

(a) If unit sales price $R$ increases, then $P\left(x_{2}\right)$ increases.

(b) If unit manufacturing cost $c_{M}$ increases, then $P\left(x_{2}\right)$ decreases.

(c) If unit holding cost rate $h_{1}$ increases, then $P\left(x_{2}\right)$ decreases.

The monotonicity of $P\left(x_{2}\right)$ with respect to the time rate parameters is presented in the following theorem. Since the results can be proven using the arguments similar to the ones in Theorem 2, we omit the proof.

\section{Theorem 3 .}
(a) If demand rate $\lambda_{1}$ increases, then $P\left(x_{2}\right)$ increases.
(b) If manufacturing rate $\mu_{1}$ increases, then $P\left(x_{2}\right)$ decreases.
(c) If recovery rate $\mu_{2}$ increase, then $P\left(x_{2}\right)$ decreases.
(d) If product return rate $\lambda_{2}$ increases, then $P\left(x_{2}\right)$ decreases. 


\section{Numerical Study}

$P\left(x_{2}\right)$ and $D\left(x_{1}\right)$, determined by Theorem 1, are fairly complex because they are characterized by state dependent threshold levels. Since the number of system states grows exponentially as $x_{1}$ and $x_{2}$ get larger, computing the optimal policy becomes intractable. Hence, motivated by the prohibitive inefficiencies associated with problems of large sizes, we introduce the heuristic solution approaches. The heuristics differ in the rule that uses $x_{1}$ and $x_{2}$ in determining production and disposal controls. Also, unlike $P\left(x_{2}\right)$ and $D\left(x_{1}\right)$ applied only to the MDP problem, the following heuritics are applicable to the non-MDP problem with general probability distributions.

The first heuristic is a base stock policy for the two-stage production system (Veach and Wein, 1994) :

- In $\left(x_{1}, x_{2}\right)$, a new item is produced when $x_{1}<H_{S}^{1}$.

- If a product return occurs in $\left(x_{1}, x_{2}\right)$, then it is accepted when $x_{1}+x_{2}<H_{S}^{1}+H_{R}^{1}$. When $x_{1}+x_{2}=H_{S}^{1}+H_{R}^{1}$, each returned item is disposed of.

The optimality equation for the base stock policy is

$v\left(x_{1}, x_{2}\right)+g_{H_{1}}=\frac{1}{\gamma}\left[-x_{1} h_{1}-x_{2} h_{2}\right.$

$+\lambda_{1}\left\{\left(R+v\left(x_{1}-1, x_{2}\right)\right) 1\left(x_{1}>0\right)+v\left(x_{1}, x_{2}\right) 1\left(x_{1}=0\right)\right\}$

$+\mu_{1}\left\{\left(v\left(x_{1}+1, x_{2}\right)-c_{M}\right) 1\left(x_{1}<H_{S}^{1}\right), v\left(x_{1} x_{2}\right) 1\left(x_{1}=H_{S}^{1}\right)\right\}$

$+\mu_{2}\left\{\left(v\left(x_{1}+1, x_{2}-1\right)-c_{R}\right) 1\left(x_{2}>0\right)+v\left(x_{1}, x_{2}\right) 1\left(x_{2}=0\right)\right\}$

$\left.+\lambda_{2}\left\{f\left(x_{1}, x_{2}+1\right) 1\left(x_{1}+x_{2}<H_{S}^{1}+H_{R}^{1}\right)+\right]\right\}$

$\left\{\left(f\left(x_{1}, x_{2}\right)-c_{D}\right) 1\left(x_{1}+x_{2}=H_{S}^{1}+H_{R}^{1}\right)\right\}$

The second heuristic is a fixed buffer policy for the two-stage production system (Veach and Wein, 1994) :

- In $\left(x_{1}, x_{2}\right)$, a new item is produced when $x_{1}<H_{S}^{2}$.

- If a product return occurs in $\left(x_{1}, x_{2}\right)$, then it is accepted when $x_{2}<H_{R}^{2}$. When $x_{2}=H_{R}^{2}$, each returned item is disposed of.

The optimality equation for the fixed buffer policy is

$v\left(x_{1}, x_{2}\right)+g_{H_{2}}=\frac{1}{\gamma}\left[-x_{1} h_{1}-x_{2} h_{2}\right.$

$+\lambda_{1}\left\{\left(R+v\left(x_{1}-1, x_{2}\right)\right) 1\left(x_{1}>0\right)+v\left(x_{1}, x_{2}\right) 1\left(x_{1}=0\right)\right\}$

$+\mu_{1}\left\{\left(v\left(x_{1}+1, x_{2}\right)-c_{M}\right) 1\left(x_{1}<H_{S}^{2}\right), v\left(x_{1} x_{2}\right) 1\left(x_{1}=H_{S}^{2}\right)\right\}$

$+\mu_{2}\left\{\left(v\left(x_{1}+1, x_{2}-1\right)-c_{R}\right) 1\left(x_{2}>0\right)+v\left(x_{1}, x_{2}\right) 1\left(x_{2}=0\right)\right\}$

$\left.+\lambda_{2}\left\{f\left(x_{1}, x_{2}+1\right) 1\left(x_{2}<H_{R}^{2}\right)+\left(f\left(x_{1}, x_{2}\right)-c_{D}\right) 1\left(x_{2}=H_{R}^{2}\right)\right\}\right]$

The third heuristic uses two linear switching functions to make production and disposal decisions as follows :

- In $\left(x_{1}, x_{2}\right)$, a new item is produced when $x_{1}+x_{2}<H_{S}^{3}$.

- If a product return occurs in $\left(x_{1}, x_{2}\right)$, then it is accepted when
$x_{1}+x_{2}<H_{R}^{3}$. When $x_{1}+x_{2}=H_{R}^{3}$, each returned item is disposed of.

The optimality equation for the third control policy is

$$
\begin{aligned}
& v\left(x_{1}, x_{2}\right)+g_{H_{3}}=\frac{1}{\gamma}\left[-x_{1} h_{1}-x_{2} h_{2}\right. \\
& +\lambda_{1}\left\{\left(R+v\left(x_{1}-1, x_{2}\right)\right) 1\left(x_{1}>0\right)+v\left(x_{1}, x_{2}\right) 1\left(x_{1}=0\right)\right\} \\
& +\mu_{1}\left\{\begin{array}{l}
\left(v\left(x_{1}+1, x_{2}\right)-c_{M}\right) 1\left(x_{1}+x_{2}<H_{S}^{3}\right), \\
v\left(x_{1}, x_{2}\right) 1\left(x_{1}+x_{2}=H_{S}^{3}\right)
\end{array}\right\} \\
& +\mu_{2}\left\{\begin{array}{l}
\left(v\left(x_{1}+1, x_{2}-1\right)-c_{R}\right) 1\left(x_{2}>0\right)+ \\
v\left(x_{1}, x_{2}\right) 1\left(x_{2}=0\right)
\end{array}\right\} \\
& \left.+\lambda_{2}\left\{\begin{array}{l}
f\left(x_{1}, x_{2}+1\right) 1\left(x_{1}+x_{2}<H_{R}^{3}\right)+ \\
\left(f\left(x_{1}, x_{2}\right)-c_{D}\right) 1\left(x_{1}+x_{2}=H_{R}^{3}\right)
\end{array}\right\}\right]
\end{aligned}
$$

Best values of $\left(H_{S}^{1^{*}}, H_{R}^{1^{*}}\right),\left(H_{S}^{2^{*}}, H_{R}^{2^{*}}\right)$, and $\left(H_{S}^{3^{*}}, H_{R}^{3^{*}}\right)$ to maximize $g_{H_{1}}, g_{H_{2}}$, and $g_{H_{3}}$, respectively, are found using a two-dimensional search on possible integer values of each pair via the value iteration algorithm presented in the appendix. Performance comparison between the optimal and heuristic policies is reported in $\langle$ Table $2>$ and $\langle$ Table $3>$. In these tables, $\%$ are obtained from $\frac{g-g_{H_{i}}}{g} \times 100, i=1,2,3$. We set $\lambda_{1}=0.5, \mu_{1}=0.6, \mu_{2}=0.9$, and $\lambda_{2}=0.25$ in $<$ Table 2>, and $R=100, h_{1}=2, h_{2}=1, c_{R}=5, c_{M}=$ 10 , and $c_{D}=3$ in $<$ Table $3>$.

The average $\%$ differences of three heuristic policies over the optimal policy show that the base stock policy and the linear switching rule performs very well. This indicates that the information of both $x_{1}$ and $x_{2}$ is very useful in determining production and disposal controls.

It is worth noting that $\left(H_{S}^{1^{*}}, H_{R}^{1^{*}}\right),\left(H_{S}^{2^{*}}, H_{R}^{2^{*}}\right)$, and $\left(H_{S}^{3^{*}}\right.$, $\left.H_{R}^{3^{*}}\right)$ are sensitive to the change of $h_{1}, c_{M}, \lambda_{1}$, and $\lambda_{2}$. For example, from <Table 2>, $\left(H_{S}^{1^{*}}, H_{R}^{1^{*}}\right),\left(H_{S}^{2^{*}}, H_{R}^{2^{*}}\right)$, and $\left(H_{S}^{3^{*}}, H_{R}^{3^{*}}\right)$ tend to decrease as $h_{1}$ increases, which leads to less production of new items and more disposal of returned items. It is also observed that as $c_{M}$ increases, $H_{R}^{1}, H_{R}^{2}$, and $H_{R}^{3}$ are increasing, which means each heuristic accepts more returned items. This makes sense because the product recovery becomes more valuable in replenishing serviceable inventory if $c_{M}$ increases. From $<$ Table $3>$, as $\lambda_{1}$ increases, $\left(H_{S}^{1^{*}}, H_{R}^{1^{*}}\right),\left(H_{S}^{2^{*}}, H_{R}^{2^{*}}\right)$, and $\left(H_{S}^{3^{*}}, H_{R}^{3^{*}}\right)$ tend to increase. With increased $\lambda_{1}$, the chance of enhancing sales revenue also increases and thus serviceable inventory becomes more valuable. Hence, the firm has an incentive to manufacture more new products and accept more returned products. In contrast, an increase in $\lambda_{2}$ tends to decrease $\left(H_{S}^{1^{*}}, H_{R}^{1^{*}}\right)$, $\left(H_{S}^{2^{*}}, H_{R}^{2^{*}}\right)$, and $\left(H_{S}^{3^{*}}, H_{R}^{3^{*}}\right)$. When $\lambda_{2}$ is increased, more serviceable products can be stocked because of increased returned products unless the control policy would be changed. Therefore, the production and disposal thresholds must be lowered to avoid excessive units in both serviceable and remanufacturable inventory. 
Table 2. Comparison of the optimal and heuristic policies : Cost parameters

\begin{tabular}{|c|c|c|c|c|c|c|c|c|c|c|c|c|c|c|c|c|c|c|c|}
\hline & \multirow{2}{*}{$R$} & \multirow[b]{2}{*}{$h_{1}$} & \multirow[b]{2}{*}{$h_{2}$} & \multirow[b]{2}{*}{$c_{R}$} & \multirow[b]{2}{*}{$c_{M}$} & \multirow[b]{2}{*}{$c_{D}$} & \multirow[b]{2}{*}{$g$} & \multicolumn{4}{|c|}{ Base stock } & \multicolumn{4}{|c|}{ Fixed buffer } & \multicolumn{4}{|c|}{ Linear switching } \\
\hline & & & & & & & & $g_{H_{1}}$ & $H_{S}^{1^{*}}$ & $H_{R}^{1^{*}}$ & $\%$ & $g_{H_{2}}$ & $H_{S}^{2^{*}}$ & $H_{R}^{2^{*}}$ & $\%$ & $g_{H_{3}}$ & $H_{S}^{3^{*}}$ & $H_{R}^{3^{*}}$ & $\%$ \\
\hline 1 & 100 & 2 & 1 & 5 & 10 & 3 & 37.05 & 37.02 & 3 & 2 & 0.08 & 36.86 & 3 & 2 & 0.51 & 37.01 & 4 & 5 & .11 \\
\hline 2 & 125 & & & & & & 48.91 & 48.75 & 4 & 2 & 0.33 & 48.51 & 4 & . & 0.82 & 8.88 & 4 & 6 & .06 \\
\hline 3 & 150 & & & & & & 60.83 & 60.73 & 4 & 2 & 0.16 & 60.52 & 4 & 2 & 0.51 & 60.78 & 4 & 6 & .08 \\
\hline 4 & 175 & & & & & & 72.75 & 72.71 & 4 & 2 & 0.05 & 72.53 & 4 & 2 & 0.30 & 72.68 & 4 & 6 & .10 \\
\hline 5 & 00 & 1.5 & 1 & 5 & 10 & 3 & 38.62 & 38.5 & 4 & 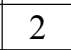 & 031 & 38.36 & 4 & 2 & & & 4 & 6 & .05 \\
\hline 6 & & 2 & & & & & 37.05 & 37.02 & 3 & 2 & 00 & 36.86 & 3 & 2 & 0.51 & 01 & 4 & 5 & 11 \\
\hline 7 & & 2.5 & & & & & 35.79 & 35.71 & 3 & 2 & 0.22 & 35.43 & 3 & 2 & 1.01 & 5.69 & 3 & 5 & .28 \\
\hline 8 & & 3 & & & & & 34.6 & 34.45 & 3 & 1 & 0.43 & 34.13 & 3 & 1 & 1.36 & 34.53 & 3 & 4 & 0.20 \\
\hline 9 & 100 & 2 & 0.5 & 5 & 10 & 3 & 37.21 & 37.17 & 3 & 2 & 0.11 & 37.02 & 3 & 2 & & 37.15 & 4 & 5 & .16 \\
\hline 10 & & & 1 & & & & 37.05 & 37.02 & 3 & 2 & 0. & 36.86 & 3 & 2 & 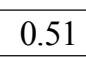 & 01 & 4 & 5 & 11 \\
\hline 11 & & & 1.5 & & & & 36.89 & 36.87 & 3 & 2 & 0.05 & 36.7 & 3 & 2 & 0.52 & 36.87 & 4 & 5 & .05 \\
\hline 12 & & & 2 & & & & 36.75 & 36.72 & 3 & 2 & 0.08 & 36.54 & 3 & 2 & 0.57 & 36.73 & 4 & 5 & 0.05 \\
\hline 13 & 100 & 2 & 1 & 2 & 10 & 3 & 37.82 & 37.77 & 3 & 3 & 0.13 & 37.64 & 3 & 2 & 0.48 & 37.74 & 4 & 6 & 0.21 \\
\hline 14 & & & & 4 & & & 37 & 37.26 & 0 & 0 & & 37.12 & 3 & 2 & 0. & 37.24 & 4 & 5 & 16 \\
\hline 15 & & & & 6 & & & 36.8 & 36.78 & 3 & 2 & 0.05 & 36.6 & 3 & 2 & 0.54 & 36.78 & 4 & 5 & .05 \\
\hline 16 & & & & 8 & & & 36.35 & 36.29 & 3 & 2 & 0.17 & 36.07 & 3 & 2 & 0.77 & 36.33 & 4 & 5 & 0.06 \\
\hline 17 & 100 & 2 & 1 & 5 & 8 & 3 & 37.57 & 37.51 & 3 & 2 & 0.16 & 37.32 & 3 & 2 & 0.67 & 37.55 & 4 & 5 & 0.05 \\
\hline 18 & & & & & 11 & & 36 & 36.77 & 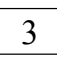 & 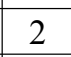 & & 36.63 & 3 & 2 & & 36.74 & 4 & 5 & .19 \\
\hline 19 & & & & & 14 & & 36.12 & 36.07 & 5 & 3 & 0.14 & 35.94 & 3 & 2 & 0. & 36.01 & 3 & 6 & 0.30 \\
\hline 20 & & & & & 17 & & 35.44 & 35.37 & 3 & 3 & 0.20 & 35.25 & 3 & 3 & 0.54 & 35.35 & 3 & 6 & 0.25 \\
\hline 21 & 100 & 2 & 1 & 5 & 10 & 11 & 37.12 & 37.08 & 3 & 2 & 0.1 & 36.89 & 3 & 2 & 0. & 37.1 & 4 & 5 & 0.05 \\
\hline 22 & & & & & & 2 & 37.08 & 37.05 & 3 & 2 & 0. & 36.87 & 3 & 2 & 0. & 37.06 & 4 & 5 & 0.05 \\
\hline 23 & & & & & & 3 & 37.05 & 37.02 & 3 & 2 & 0.08 & 36.86 & 3 & 2 & 0. & 37.01 & 4 & 5 & 0.11 \\
\hline 24 & & & & & & 4 & 37.02 & 36.99 & 3 & 2 & 0.08 & 36.84 & 3 & 2 & 0.49 & 36.97 & 4 & 5 & 0.14 \\
\hline & & & & & & & nali & & & & 0.14 & & & & 0.6 & & & & 0.13 \\
\hline
\end{tabular}

Table 3. Comparison of the optimal and heuristic policies : Time parameters

\begin{tabular}{|c|c|c|c|c|c|c|c|c|c|c|c|c|c|c|c|c|c|}
\hline & \multirow{2}{*}{$\lambda_{1}$} & \multirow[b]{2}{*}{$\mu_{1}$} & \multirow[b]{2}{*}{$\mu_{2}$} & \multirow{2}{*}{$\lambda_{2}$} & \multirow[b]{2}{*}{$g$} & \multicolumn{4}{|c|}{ Base stock } & \multicolumn{4}{|c|}{ Fixed buffer } & \multicolumn{4}{|c|}{ Linear switching } \\
\hline & & & & & & $g_{H_{1}}$ & $H_{S}^{1^{*}}$ & $H_{R}^{1^{*}}$ & $\%$ & $g_{H_{2}}$ & $H_{S}^{2^{*}}$ & $H_{R}^{2^{*}}$ & $\%$ & $g_{H_{3}}$ & $H_{S}^{3^{*}}$ & $H_{R}^{3^{*}}$ & $\%$ \\
\hline 1 & 0.35 & 0.6 & 0.9 & 0.25 & 25.39 & 25.37 & 2 & 2 & 0.08 & 24.88 & 2 & 1 & 2.01 & 25.26 & 3 & 4 & 0.51 \\
\hline 2 & 0.45 & & & & 33.31 & 33.21 & 3 & 2 & 0.30 & 32.96 & 3 & 1 & 1.05 & 33.24 & 3 & 5 & 0.21 \\
\hline 3 & 0.55 & & & & 40.88 & 40.74 & 4 & 2 & 0.34 & 40.6 & 4 & 2 & 0.68 & 40.85 & 4 & 6 & 0.07 \\
\hline 4 & 0.65 & & & & 48.09 & 47.95 & 5 & 2 & 0.29 & 47.9 & 5 & 3 & 0.40 & 48.07 & 5 & 7 & 0.04 \\
\hline 5 & 0.5 & 0.55 & 0.9 & 0.25 & 36.78 & 36.67 & 3 & 2 & 0.30 & 36.53 & 3 & 2 & 0.68 & 36.76 & 4 & 5 & 0.05 \\
\hline 6 & & 0.65 & & & 37.34 & 37.3 & 3 & 2 & 0.11 & 37.12 & 3 & 2 & 0.59 & 37.22 & 3 & 5 & 0.32 \\
\hline 7 & & 0.75 & & & 37.82 & 37.73 & 3 & 2 & 0.24 & 37.53 & 3 & 1 & 0.77 & 37.72 & 3 & 5 & 0.26 \\
\hline 8 & & 0.85 & & & 38.17 & 38.03 & 3 & 2 & 0.37 & 37.87 & 3 & 1 & 0.79 & 38.07 & 3 & 5 & 0.26 \\
\hline 9 & 0.5 & 0.6 & 0.6 & 0.25 & 36.26 & 36.15 & 3 & 2 & 0.30 & 36.02 & 3 & 2 & 0.66 & 36.13 & 4 & 5 & 0.36 \\
\hline 10 & & & 0.8 & & 36.84 & 36.8 & 3 & 2 & 0.11 & 36.65 & 3 & 2 & 0.52 & 36.81 & 4 & 5 & 0.08 \\
\hline 11 & & & 1 & & 37.22 & 37.19 & 3 & 2 & 0.08 & 37.02 & 3 & 2 & 0.54 & 37.16 & 4 & 5 & 0.16 \\
\hline 12 & & & 1.2 & & 37.47 & 37.44 & 3 & 2 & 0.08 & 37.27 & 3 & 2 & 0.53 & 37.44 & 3 & 5 & 0.08 \\
\hline 13 & 0.5 & 0.6 & 0.9 & 0.1 & 35.88 & 35.84 & 4 & 2 & 0.11 & 35.84 & 4 & 3 & 0.11 & 35.87 & 4 & 6 & 0.03 \\
\hline 14 & & & & 0.2 & 36.77 & 36.62 & 4 & 2 & 0.41 & 36.57 & 3 & 2 & 0.54 & 36.75 & 4 & 6 & 0.05 \\
\hline 15 & & & & 0.3 & 37.33 & 37.29 & 3 & 2 & 0.11 & 36.9 & 3 & 1 & 1.15 & 37.18 & 4 & 5 & 0.40 \\
\hline 16 & & & & \begin{tabular}{|l|} 
\\
\end{tabular} & 37.66 & 37.53 & 3 & 2 & 0.35 & 36.99 & 3 & 1 & 1.78 & 37.43 & 3 & 5 & 0.61 \\
\hline \multicolumn{9}{|c|}{ Average $\%$ of optimality gap } & 0.22 & & & & 0.8 & & & & 0.22 \\
\hline
\end{tabular}




\section{Conclusions}

This paper studied the joint control of production and disposal decisions for a hybrid system with a disposal option. When both holding cost rates of serviceable and remanufacturable inventories are equal, we showed that the optimal joint decisions are controlled by two monotone switching curves. In addition, when a disposal control is a threshold rule, we showed that the optimal production switching curve is monotonically affected by the changes in system parameters. From the inventory policies for forward supply chain models, we developed three heuristic policies. Numerical experiment demonstrated that the heuristics defined by both serviceable and remanufacturable inventories are effective.

One can extend the model into a situation where the quality of remanufactured product is not the same as that of a new product. In such a situation, a portfolio of new and remanufactured products will become important because the remanufactured product reduces the sales of the new product when sold on the same market. Another important future direction is to consider situations where the product return intensity is varied by the compensation given to customers and there is a random yield in the remanufacturing process due to the uncertain quality of the returned items.

\section{References}

DeCroix, G. (2006), Optimal policy for a multiechelon inventory system with remanufacturing, Operations Research, 54, 532-543.

Fleischmann, M. (2000), Quantitative models for reverse logistics, Ph.D. thesis, Erasmus University, Rotterdam, The Netherlands.

Fleischmann, M. and Kuik, R. (2003), On optimal inventory control with independent stochastic item returns, European Journal of Operational Research, 151, 25-37.

Heyman, D. (1977), Optimal disposal policies for a single item inventory system with returns, Naval Research Logistics, 24, 385-405.

Inderfurth, K. (1997), Simple optimal replenishment and disposal policies for a product recovery system with lead times, OR Spektrum, 19, 111-122.

Inderfurth, K. and van der Laan, E. (2001), Leadtime effects and policy improvement for stochastic inventory control with remanufacturing, International Journal of Production Economics, 71, 381-390.

Li, X., Li, Y., and Saghafian, S. (2013), A hybrid manufacturing/remanu- facturing system with random remanufacturing yield and marketdriven product acquisition, To apear in IEEE Transactions on Engineering Management.

Mahadevan, B., Pyke, D., and Fleischmann, M. (2003), Periodic review, push inventory policies for remanufacturing, European Journal of Operational Research, 151, 536-551.

Muckstadt, J. and Isaac, M. (1981), An analysis of single item inventory systems with returns, Naval Research Logistics, 28, 237-254.

Porteus, E. (1982), Conditions for characterizing the structure of optimal strategies in infinite-horizon dynamic programs, Journal of Optimization Theory and Applications, 36, 419-432.

Puterman, M. (2005), Markov Decision Processes, John Wiley and Sons.

Simpson, V. (1978), Optimal solution structure for a repairable inventory problem, Operations Research, 26, 270-281.

Teunter, R. and Vlachos, D. (2002), On the necessity of a disposal option for returned items that can be remanufactured, International Journal of Production Economics, 75, 257-266.

Teunter, R., van der Laan, E., and Vlachos, D. (2004), Inventory strategies for systems with fast remanufacturing, The Journal of Operational Research Society, 55, 475-484.

van der Laan, E., Dekker, R., and Salomon, M. (1996a), Product remanufacturing and disposal : A numerical comparison of alternative control strategies, International Journal of Production Economics, 45, 489498.

van der Laan, E., Dekker, R., and Salomon, M., and Ridder, A. (1996b), An (s, Q) inventory model with remanufacturing and disposal, International Journal of Production Economics, 46, 339-350.

van der Laan, E. and Salomon, M. (1997), Production planning and inventory control with remanufacturing and disposal, European Journal of Operational Research, 102, 264-278.

van der Laan, E., Salomon, M., and Dekker, R. (1999a), An investigation of lead-time effects in manufacturing/remanufacturing systems under simple PUSH and PULL control strategies, European Journal of Operational Research, 115, 195-214.

van der Laan, E., Salomon, M., Dekker, R., and Van Wassenhove, L. (1999b), Inventory control in hybrid systems with remanufacturing, Management Science, 45, 733-747.

van der Laan, E. A. and Teunter, R. (2006), Simple heuristics for push and pull remanufacturing policies, European Journal of Operational Research, 175, 1084-1102.

Veatch, M. and Wein, L. (1994), Optimal control of a two-station tandem production/inventory system, Operations Research, 42, 337-350.

Wei, C., Li, Y., and Cai, X. (2009), Robust optimal policies of production and inventory with uncertain returns and demand, International Journal of Production Economics, 134, 357-367.

Zhou, S., Tao, Z. and Chao, X. (2011), Optimal control of inventory systems with multiple types of remanufacturable products, Manufacturing and Service Operations Management, 13, 20-34. 


\section{$<$ Appendix A>}

We denote by $P, N, D$, and $A$ the optimal actions in state $\left(x_{1}, x_{2}\right)$ where $P, N, D$, and $A$ respectively represent Produce, Do not produce, Dispose of, and Accept. Define

$$
\begin{aligned}
& T_{1} f\left(x_{1}, x_{2}\right)=\left(R+f\left(x_{1}-1, x_{2}\right)\right) 1\left(x_{1}>0\right)+f\left(x_{1}, x_{2}\right) 1\left(x_{1}=0\right), \\
& T_{2} f\left(x_{1}, x_{2}\right)=\max \left\{-c_{M}+f\left(x_{1}+1, x_{2}\right), f\left(x_{1}, x_{2}\right)\right\}, \\
& T_{3} f\left(x_{1}, x_{2}\right)=\left(f\left(x_{1}+1, x_{2}-1\right)-c_{R}\right) 1\left(x_{2}>0\right)+f\left(x_{1}, x_{2}\right) 1\left(x_{2}=0\right), \\
& T_{4} f\left(x_{1}, x_{2}\right)=\max \left\{f\left(x_{1}, x_{2}+1\right), f\left(x_{1}, x_{2}\right)-c_{D}\right\} .
\end{aligned}
$$

Then, the value iteration operator $T$ on $f$ can be written as

$$
T f\left(x_{1}, x_{2}\right)=\frac{1}{\gamma}\left[-x_{1} h_{1}-x_{2} h_{2}+\lambda_{1} T_{1} f\left(x_{1}, x_{2}\right)+\mu_{1} T_{2} f\left(x_{1}, x_{2}\right)+\mu_{2} T_{3} f\left(x_{1}, x_{2}\right)+\lambda_{2} T_{4} f\left(x_{1}, x_{2}\right)\right] .
$$

\section{Proof of Lemma 1 :}

(i) Since $D_{1} f\left(x_{1}, x_{2}\right)-D_{1} f\left(x_{1}, x_{2}+1\right)=D_{2} f\left(x_{1}, x_{2}\right)-D_{2} f\left(x_{1}+1, x_{2}\right)$, we show the case with $i=1$ and $j=2$. Let $\Delta^{k}=D_{1} T_{k} f\left(x_{1}, x_{2}\right)-D_{1} T_{k} f\left(x_{1}, x_{2}+1\right)$.

First, we show $\Delta^{k} \geq 0, k=1,2,3,4$.

$$
\begin{aligned}
& \Delta^{1} \geq 0 \text { by (2) if } x_{1}>0 \text { and } \Delta^{1}=0 \text { if } x_{1}=0 . \\
& \Delta^{3} \geq 0 \text { by (2) if } x_{2}>0 \text { and } \Delta^{3}=D_{1} f\left(x_{1}, 0\right)-D_{1} f\left(x_{1}+1,0\right) \geq 0 \text { by (4) if } x_{2}=0 .
\end{aligned}
$$

To show $\Delta^{2} \geq 0$ and $\Delta^{3} \geq 0$, consider production and disposal controls in $\left(x_{1}+1, x_{2}\right),\left(x_{1}, x_{2}\right)$,

$$
\left(x_{1}+1, x_{2}+1\right) \text {, and }\left(x_{1}, x_{2}+1\right) \text { : }
$$

- Cases $(P, N, \cdot, \cdot)$ and $(\cdot, \cdot, P, N)$ are excluded by $(4),(P, \cdot, \cdot, N)$ by $(3)$, and $(\cdot, N, \cdot, P)$ and $(N, \cdot, P, \cdot)$ by $(2)$.

Cases $(N, N, N, N)$ and $(P, P, P, P)$ follow by (2).

For $(N, P, N, P),(N, P, N, N)$, and $(P, P, N, P)$,

$$
\Delta^{2} \geq f\left(x_{1}+1, x_{2}\right)-\left(f\left(x_{1}+1, x_{2}\right)-c_{M}\right)-\left[f\left(x_{1}+1, x_{2}+1\right)-\left(f\left(x_{1}+1, x_{2}+1\right)-c_{M}\right)\right]=0 .
$$

- Cases $(A, D, \cdot, \cdot)$ and $(\cdot, \cdot, A, D)$ are excluded by $(2),(D, \cdot, A, \cdot)$ and $(\cdot, D, \cdot, A)$ by (4), and $(D, \cdot, \cdot, A)$ by $(3)$.

Cases $(A, A, A, A)$ and $(D, D, D, D)$ follow by (2).

For $(A, A, D, D),(D, A, D, D)$, and $(A, A, D, A)$,

$$
\Delta^{4} \geq f\left(x_{1}+1, x_{2}+1\right)-f\left(x_{1}, x_{2}+1\right)-\left[\left(f\left(x_{1}+1, x_{2}+1\right)-c_{D}\right)-\left(f\left(x_{1}, x_{2}+1\right)-c_{D}\right)\right]=0 .
$$

Therefore, $T D_{1} f\left(x_{1}, x_{2}\right)-T D_{1} f\left(x_{1}, x_{2}+1\right)=1 / \gamma\left[\lambda_{1} \Delta^{1}+\mu_{1} \Delta^{2}+\mu_{2} \Delta^{3}+\lambda_{2} \Delta^{4}\right] \geq 0$.

(ii) Suppose that $i=1$ and $j=2$.

$$
\text { Let } \Delta^{k}=D_{1} T_{k} f\left(x_{1}, x_{2}+1\right)-D_{1} T_{k} f\left(x_{1}+1, x_{2}\right) \text {. }
$$

$\Delta^{1} \geq 0$ by (3) if $x_{1}>0$ and $\Delta^{1}=R+f\left(0, x_{2}+1\right)-f\left(0, x_{2}+1\right)-D_{1} f\left(0, x_{2}\right) \geq 0$ by (5) if $x_{1}=0$.

$\Delta^{3} \geq 0$ by (3) if $x_{2}>0$ and $\Delta^{3}=D_{1} f\left(x_{1}+1,0\right)-D_{1} f\left(x_{1}+1,0\right)=0$ if $x_{2}=0$.

To show $\Delta^{2} \geq 0$ and $\Delta^{4} \geq 0$, consider production and disposal controls in $\left(x_{1}+1, x_{2}+1\right),\left(x_{1}, x_{2}+1\right)$, $\left(x_{1}+2, x_{2}\right)$, and $\left(x_{1}+1, x_{2}\right)$ :

- Cases $(P, N, \cdot, \cdot)$ and $(\cdot, \cdot, P, N)$ are excluded by $(4),(P, \cdot, \cdot, N)$ by $(2)$, and $(\cdot, N, \cdot, P)$ and $(N, \cdot, P, \cdot)$ by $(3)$.

Cases $(P, P, P, P)$ and $(N, N, N, N)$ follow by (3).

For $(N, P, N, P),(P, P, N, P)$, and $(N, P, N, N), \Delta^{2} \geq c_{M}-c_{M}=0$.

- Cases $(A, D, \cdot, \cdot)$ and $(\cdot, \cdot, A, D)$ are excluded by $(2),(A, \cdot, D, \cdot)$ and $(\cdot, A, \cdot, D)$ by $(3)$, and $(A, \cdot, \cdot, D)$ by $(4)$.

Cases $(A, A, A, A),(D, D, D, D),(D, D, D, A)$, and $(D, A, A, A)$ follow by (3).

For $(D, A, D, A), \Delta^{4}=-c_{D}+f\left(x_{1}+1, x_{2}+1\right)-f\left(x_{1}, x_{2}+2\right)-\left[-c_{D}+f\left(x_{1}+2, x_{2}\right)-f\left(x_{1}+1, x_{2}+1\right)\right] \geq$ $f\left(x_{1}, x_{2}+1\right)-f\left(x_{1}+1, x_{2}\right)-\left[f\left(x_{1}, x_{2}+2\right)-f\left(x_{1}+1, x_{2}+1\right)\right] \geq 0$. The inequalities follows by (3). 
Suppose that $i=2$ and $j=1$. Let $\Delta^{k}=D_{2} T_{k} f\left(x_{1}+1, x_{2}\right)-D_{2} T_{k} f\left(x_{1}, x_{2}+1\right)$.

$\Delta^{1} \geq 0$ by (3) if $x_{1}>0$ and $\Delta^{1}=D_{2} f\left(0, x_{2}\right)-D_{2} f\left(0, x_{2}+1\right) \geq 0$ by (4) if $x_{1}=0$.

$\Delta^{3} \geq 0$ by (3) if $x_{2}>0$ and $\Delta^{3}=f\left(x_{1}+2,0\right)-c_{R}-f\left(x_{1}+1,1\right) \geq 0$ by (6) if $x_{2}=0$.

To show $\Delta^{2} \geq 0$ and $\Delta^{4} \geq 0$, consider production and disposal controls in $\left(x_{1}+1, x_{2}+1\right),\left(x_{1}+1, x_{2}\right)$, $\left(x_{1}, x_{2}+2\right)$, and $\left(x_{1}, x_{2}+1\right)$ :

- Cases $(P, N, \cdot, \cdot)$ and $(\cdot, \cdot, P, N)$ are excluded by $(2),(\cdot, P, \cdot, N)$ and $(P, \cdot, N, \cdot)$ by (3).

and $(P, \cdot, \cdot, N)$ by $(4)$.

Cases $(P, P, P, P),(N, N, N, N),(N, P, P, P)$, and $(N, N, N, P)$ follow by (3).

For $(N, N, P, P), \Delta^{2}=D_{2} f\left(x_{1}+1, x_{2}\right)-D_{2} f\left(x_{1}+1, x_{2}+1\right) \geq 0$ by $(4)$.

For $(N, P, N, P), \Delta^{2}=f\left(x_{1}+1, x_{2}+1\right)-\left(f\left(x_{1}+2, x_{2}\right)-c_{M}\right)-\left[f\left(x_{1}, x_{2}+2\right)-\left(f\left(x_{1}+1, x_{2}+1\right)\right.\right.$

$\left.\left.-c_{M}\right)\right] \geq f\left(x_{1}+1, x_{2}\right)-f\left(x_{1}+2, x_{2}\right)-\left(f\left(x_{1}, x_{2}+1\right)-f\left(x_{1}+1, x_{2}+1\right) \geq 0\right.$.

The inequalities follow by (3).

- Cases $(A, D, \cdot, \cdot)$ and $(\cdot, \cdot, A, D)$ are excluded by $(4),(D, \cdot, A, \cdot)$ and $(\cdot, D, \cdot, A)$ by (3),

and $(A, \cdot, \cdot, D)$ by $(2)$.

Cases $(A, A, A, A)$ and $(D, D, D, D)$ follow by (3).

For $(D, A, D, A),(D, A, D, D)$, and $(A, A, D, A)$,

$\Delta^{4} \geq f\left(x_{1}+1, x_{2}+1\right)-c_{D}-f\left(x_{1}+1, x_{2}+1\right)-\left[f\left(x_{1}, x_{2}+2\right)-c_{D}-f\left(x_{1}, x_{2}+2\right)\right]=0$.

Since $\Delta^{k} \geq 0$,

$k=1,2,3,4, \Delta_{i} \operatorname{Tf}\left(x_{i}, x_{j}+1\right)-\Delta_{i} \operatorname{Tf}\left(x_{i}+1, x_{j}\right)=1 / \gamma\left[\lambda_{1} \Delta^{1}+\mu_{1} \Delta^{2}+\mu_{2} \Delta^{3}+\lambda_{2} \Delta^{4}\right] \geq 0$.

(iii) $D_{i} T f\left(x_{i}, x_{j}\right) \geq D_{i} T f\left(x_{i}, x_{j}+1\right)$ (by (2)) $\geq D_{i} T f\left(x_{i}+1, x_{j}\right)$ by (3).

(iv) $D_{1} T_{1} f\left(x_{1}, x_{2}\right)=R 1\left(x_{1}=0\right)+D_{1} f\left(x_{1}-1, x_{2}\right) 1\left(x_{1}>0\right) \leq R$ by (5).

For $k=2,3,4, D_{1} T_{k} f\left(x_{1}, x_{2}\right) \leq R$ by (5).

Therefore, $D_{1} T f\left(x_{1}, x_{2}\right) \leq 1 / \gamma\left[-h_{1}+\left(\lambda_{1}+\mu_{1}+\mu_{2}+\lambda_{2}\right) R\right] \leq R$.

(v) Let $\Delta^{k}=T_{k} f\left(x_{1}+1, x_{2}\right)-T_{k} f\left(x_{1}, x_{2}+1\right)$. If $x_{1}>0, \Delta^{1} \geq c_{R}$ by (6).

If $x_{1}=0, \Delta^{1}=R+f(0,0)-f(0,1) \geq f(1,0)-f(0,1)$ (by (5)) $\geq c_{R}$ by (6).

It can be easily shown that $\Delta^{2} \geq c_{R}$ and $\Delta^{4} \geq c_{R}$ by (6).

$\Delta^{3} \geq c_{R}$ by (6) when $x_{2}>0$ and $\Delta^{3}=f\left(x_{1}+1,0\right)-\left(f\left(x_{1}+1,0\right)-c_{R}\right)=c_{R}$ when $x_{2}=0$.

Therefore, $\operatorname{Tf}\left(x_{1}+1, x_{2}\right)-\operatorname{Tf}\left(x_{1}, x_{2}+1\right)=1 / \gamma\left[-h_{1}+h_{2}+\lambda_{1} \Delta^{1}+\mu_{1} \Delta^{2}+\mu_{2} \Delta^{3}+\lambda_{2} \Delta^{4}\right]$

$\geq 1 / \gamma\left[-h_{1}+h_{2}+\gamma c_{R}\right]=c_{R}$, since $h_{1}=h_{2}$.

\section{Proof of Theorem 1 :}

(i) Since the control with allowing the serviceable and remanufacturable inventories to go to the infinity cannot be optimal, the original problem with infinite state space can be converted into one with finite state space. Since the model has a finite action space and is unichain and aperiodic, the result follows from Theorem 8.4.5 of Puterman (2005).

(ii) From the definition of $P\left(x_{2}\right),-c_{M}+v\left(P\left(x_{2}\right)+1, x_{2}\right) \geq v\left(P\left(x_{2}\right), x_{2}\right)$.

Then, by (4), $-c_{M}+v\left(P\left(x_{2}\right), x_{2}\right) \geq v\left(P\left(x_{2}\right)-1, x_{2}\right)$, which means it is optimal to produce in $\left(P\left(x_{2}\right)-1, x_{2}\right)$. From the definition of $D\left(x_{1}\right), v\left(x_{1}, D\left(x_{1}\right)+1\right) \leq v\left(x_{1}, D\left(x_{1}\right)\right)-c_{D}$.

Then, by (4), $v\left(x_{1}, D\left(x_{1}\right)+2\right) \leq v\left(x_{1}, D\left(x_{1}\right)+1\right)-c_{D}$, which means it is optimal to dispose of a returned item in $\left(x_{1}, D\left(x_{1}\right)+1\right)$.

(iii) From the definition of $P\left(x_{2}+1\right),-c_{M}+v\left(P\left(x_{2}+1\right)+1, x_{2}+1\right) \geq v\left(P\left(x_{2}+1\right), x_{2}+1\right)$.

Then, from (2), $-c_{M}+v\left(P\left(x_{2}+1\right)+1, x_{2}\right) \geq v\left(P\left(x_{2}+1\right), x_{2}\right)$, which means $P\left(x_{2}\right) \geq P\left(x_{2}+1\right)$.

(iv) From the definition of $D\left(x_{1}\right), v\left(x_{1}, D\left(x_{1}\right)+1\right) \leq v\left(x_{1}, D\left(x_{1}\right)\right)-c_{D}$.

Then, from (2), $v\left(x_{1}+1, D\left(x_{1}\right)+1\right) \leq v\left(x_{1}+1, D\left(x_{1}\right)\right)-c_{D}$, which means $D\left(x_{1}\right) \geq D\left(x_{1}+1\right)$. 


\section{Proof of Theorem 2 :}

We prove (b). Results (a) and (c) can be shown in a similar way. Consider two hybrid systems with $c_{M}^{A}$ and $c_{M}^{B}$ where $c_{M}^{A}<c_{M}^{B}$. Consider the following equation established by $f^{A}$ and $f^{B}$ :

$$
D_{1} f^{A}\left(x_{1}, x_{2}\right)-c_{M}^{A} \geq D_{1} f^{B}\left(x_{1}, x_{2}\right)-c_{M}^{B}
$$

(12) implies that the marginal benefit of producing a new product is smaller with a higher $c_{M}$.

$T_{1}, T_{2}$, and $T_{3}$ are the same as before and let $T_{4} f\left(x_{1}, x_{2}\right) \equiv f\left(x_{1}, x_{2}+1\right) 1\left(x_{2}<M\right)+\left(f\left(x_{1}, x_{2}\right)-c_{D}\right) 1\left(x_{2}=M\right)$. Let $\Delta^{k}=D_{1} T_{k} f^{A}\left(x_{1}, x_{2}\right)-D_{1} T_{k} f^{B}\left(x_{1}, x_{2}\right)$.

Then, $\Delta^{1}$ : If $x_{1}>0, \Delta^{1} \geq c_{M}^{A}-c_{M}^{B}$ by (12).

$$
\text { If } x_{1}=0, \Delta^{1}=0 \geq c_{M}^{A}-c_{M}^{B} \text {. }
$$

$\Delta^{2}$ : Consider production controls in states $\left(x_{1}+1, x_{2}\right)^{A},\left(x_{1}, x_{2}\right)^{A},\left(x_{1}+1, x_{2}\right)^{B}$, and $\left(x_{1}, x_{2}\right)^{B}$.

Cases $(P, N, \cdot, \cdot)$ and $(\cdot, \cdot, P, N)$ are excluded by $(4)$, and $(N, \cdot, P, \cdot)$ and $(\cdot, N, \cdot, P)$ by $(12)$. Cases $(P, P, P, P)$ and $(N, N, N, N)$ follow by (12).

For $(N, P, N, P)$ and $(N, P, N, N)$, $\Delta^{2} \geq f^{A}\left(x_{1}+1, x_{2}\right)-\left(f^{A}\left(x_{1}+1, x_{2}\right)-c_{M}^{A}\right)-\left[f^{B}\left(x_{1}+1, x_{2}\right)-\left(f^{B}\left(x_{1}+1, x_{2}\right)-c_{M}^{B}\right)\right]=c_{M}^{A}-c_{M}^{B}$. Cases $(P, P, N, P)$ and $(P, P, N, N)$ can be shown in a similar way.

$\Delta^{3}: \Delta^{3} \geq c_{M}^{A}-c_{M}^{B}$ follows by (12).

$\Delta^{4}: \Delta^{4}=D_{1} f^{A}\left(x_{1}, x_{2}+1\right)-D_{1} f^{B}\left(x_{1}, x_{2}+1\right)$ when $x_{2}<M$. When $x_{2}=M$, $\Delta^{4}=D_{1} f^{A}\left(x_{1}, M\right)-D_{1} f^{B}\left(x_{1}, M\right)$. By (12), both cases $\geq c_{M}^{A}-c_{M}^{B}$.

Since (12) is preserved under $T_{1}, T_{2}, T_{3}$, and $T_{4}$, (12) is also preserved under $T$. Finally, by the definition of $P^{B}\left(x_{2}\right)$, $f^{B}\left(P^{B}\left(x_{2}\right)+1, x_{2}\right)-c_{M}^{B} \geq f^{B}\left(P^{B}\left(x_{2}\right), x_{2}\right)$. Then, from (12), $f^{A}\left(P^{B}\left(x_{2}\right)+1, x_{2}\right)-c_{M}^{A} \geq f^{A}\left(P^{B}\left(x_{2}\right), x_{2}\right)$, which means $P^{A}\left(x_{2}\right) \geq P^{B}\left(x_{2}\right)$.

\section{$<$ Appendix B $>$}

We present the value iteration algorithm to find $g$. To find $g_{H_{1}}, g_{H_{2}}$, and $g_{H_{3}}$, (12) should be replaced with the value iteration equation corresponding to (8), (9), and (10), respectively. Denote by $\epsilon$ the termination criterion of the algorithm.

1. Initialization : Set $k=0$. For each state $\left(x_{1}, x_{2}\right)$, set $v^{0}\left(x_{1}, x_{2}\right)=0$.

2. Value iteration : Implement a VI on the current value function estimate $v^{k}$ :

$$
\begin{aligned}
& T v^{k}\left(x_{1}, x_{2}\right)=\frac{1}{\gamma}\left[-\left(x_{1} h_{1}+x_{2} h_{2}\right)\right. \\
& +\lambda_{1}\left\{\left(R+v^{k}\left(x_{1}-1, x_{2}\right)\right) 1\left(x_{1}>0\right)+v^{k}\left(x_{1}, x_{2}\right) 1\left(x_{1}=0\right)\right\} \\
& +\mu_{1} \max \left\{-c_{M}+v^{k}\left(x_{1}+1, x_{2}\right), v^{k}\left(x_{1}, x_{2}\right)\right\} \\
& +\mu_{2}\left\{\left(v^{k}\left(x_{1}+1, x_{2}-1\right)-c_{R}\right) 1\left(x_{2}>0\right)+v^{k}\left(x_{1}, x_{2}\right) 1\left(x_{2}=0\right)\right\} \\
& \left.+\lambda_{2} \max \left\{v^{k}\left(x_{1}, x_{2}+1\right), v^{k}\left(x_{1}, x_{2}\right)-c_{D}\right\}\right]
\end{aligned}
$$

3. Termination test : Let $\underline{b_{k}}=\min _{\left(x_{1}, x_{2}\right)}\left\{T v^{k}\left(x_{1}, x_{2}\right)-v^{k}\left(x_{1}, x_{2}\right)\right\}$ and $\overline{b_{k}}=\max _{\left(x_{1}, x_{2}\right)}\left\{T v^{k}\left(x_{1}, x_{2}\right)-v^{k}\left(x_{1}, x_{2}\right)\right\}$. If $\left(\overline{\overline{b_{k}}}-\underline{b_{k}}\right) \geq \epsilon$ for every state $\left(x_{1}, x_{2}\right)$, set $v^{k+1}\left(x_{1}, x_{2}\right) \equiv T v^{k}\left(x_{1}, x_{2}\right)-T v^{k}(0,0)$, increase $k$ by one, and go to Value iteration. Otherwise, go to Evaluation.

4. Evaluation : The optimal average profit is approximated by $g \approx\left(\overline{b_{n}}+\underline{b_{n}}\right) / 2$. Stop the procedure. 